\title{
SMALL RETAILER EMPLOYMENT OF OLDER WORKERS: AN ASSESSMENT
}

\author{
Robin T. Peterson \\ New Mexico State University \\ Las Cruces, New Mexico
}

\begin{abstract}
This paper focuses on a study which examined the employment of older workers by small retailers in the United States. It considers the literature on the future role of senior employees in the economy, the merits of hiring these individuals, their needs, and steps which can be undertaken to improve their motivation and make them more productive. Further, it sets forth the results of an empirical investigation into the senior citizen employment practices of small retailers, advantages and disadvantages of employing seniors, and expected future employment trends. The manuscript concludes with a discussion of the implications of these patterns for small retailers.
\end{abstract}

\section{Introduction}

The past several decades have witnessed an aging of the United States population, as those in the baby boom generation and their progeny move on into maturity. This trend continues, as the median age of the country advances rapidly and steadily with the passage of time (Moyers \& Dale, 2004). Improvements in nutritional practices, exercise patterns, and medical care have resulted in larger numbers of individuals who reach age 65 and beyond. In turn, many of these experience mental and physical health status that is superior to that of previous generations. Further, large numbers of seniors evidence a preference for expanding their working years beyond age sixty-five, either on a full-time or a part-time basis (Dychtwald, Erickson, \& Morison, 2004).

Some small retailers are confronted with difficulty in recruiting, hiring and retaining capable employees and have vacant positions in both the skilled and unskilled ranks (Kraut, 2005). This pattern is perhaps most evident in regions of the country experiencing substantial economic growth, such as portions of the Southwest and Southeast. Various means of acquiring additional sought employees are available, but one that appears to possess considerable potential is to hire and retain older workers. For some small retailers, this may be the superior alternative (Peterson \& Spiker, 2005). 


\section{Objectives of the Study}

The study which this manuscript addresses focused on several objectives:

1. To provide insights on the degree to which small retailers in the United States employ older workers.

2. To uncover advantages of employing older workers, in the opinion of small retailers.

3. To uncover problems associated with employing older workers, in the opinion of small retailers.

4. To assess expected future hiring and retention intentions for older workers among small retailers.

\section{Review of the Literature}

The literature contains various articles which consider recruiting, hiring, and retaining seniors for positions in business and not-for profit organizations (Sullivan \& Duplaga, 1997). However, a substantial proportion of the studies cited in the articles have been generic and have not focused on small business in general or small retailing in particular (Greller \& Stroh, 2004). Further, some of the literature contains narratives reflecting the authors' opinions and case studies of individual firms, rather than statistical analysis which considers multiple companies (Bell, 2001). While valuable, these inquiries do not provide comprehensive coverage of the status of small retail business employment patterns.

Studies indicate that the workforce in the United States is aging rapidly and will continue to do so well into the twenty-first century ( Purcell, 2005; Fusaro, 2001). Current labor shortages were caused by unusually low birth rates among Baby Boomers and recent (sometimes early) retirements by these individuals. In turn, the shortages are particularly acute in various skill-demanding occupations, and in some parts of the country. Given the relatively small magnitude of new entrants into the labor force and the potentially large number of Boomer retirements on the horizon, labor shortages are likely to become significant during upcoming decades. (McEvoy \& Blahna, 2001).

The Baby Boomers are aging, and this is important since 55 and older individuals make up the fastest-growing segment of the workplace (Albright \& Cluff, 2005; Barrier, 2002). And some take early retirement. This creates potential job opportunities for those age 65 and older. Yet many small retailers are not actively seeking older workers, promoting them, or taking other steps to retain those already employed (Adams, 2002). In a positive vein, however, some seniors, made up of early retirees from large businesses, have formed a large number of small retail businesses and are actively involved in engaging older workers (Minerd, 1999).

The impact of Baby Boomer retirements on the economy and on specific occupations and industries, including small retailing, could be substantial-a work force short on workers and long on retirees. According to one consultant the aging workforce promises to restructure the economy, reshape the family, redefine 
politics and even rearrange the geopolitical order of the next century. Unlike many predictions, global aging is no mere hypothesis: Its approximate timing and magnitude are already locked in. (Van Yoder, 2002).

Research suggests that many workers who are age sixty-five and older are very productive and motivated members of the work force (Anonymous, 2003; Swanson, Kopecky, \& Tucker, 1997; Bell, 2001; Welbourne \& Cyr, 1999; Kraut, 2005). Various employers have come to prefer seniors because of their experience, possession of the work ethic, and lack of need for extensive training (McShulskis, 1997). Research by the Independent Institute for Employment Studies suggests that older workers are more committed and reliable, have better customer- facing skills, understand business better, and take less time in short term sickness absence (Anonymous, 1999). Further, these individuals are willing to work at a variety of schedules and can serve as mentors (Challenger, 2004; Anonymous, 2003) Other research indicates that many seniors have a strong service orientation, a positive attitude toward work, and experience less turnover than do their younger counterparts (Tshirhart, 1998; Finegold, Mohrman, \& Spreitzer, 2002). Still other studies indicate that seniors often work well with others and have well-developed interpersonal skills (Anonymous, 2001;Halachmi, 1998).

In a review by Crampton, Hodge, \& Mistra (1996), older workers are reported as enjoying themselves more on the job and less concerned with advancement, more loyal to the company than other employees, and possessing high morale. Tschirhart (1998) indicates that over 60 workers are receptive to feedback and perceived their work to be more meaningful than do younger employees. Studies in psychology have discovered that men and women in the age group 55 to 72 scored as well or better than those in younger groupings in ability to handle complex tasks, capacity for multitasking, and productivity (Bushko \& Raynor, 1999). In sum, the literature contains multiple citations to the effect that older workers possess capabilities which can enable them to be very productive employees of small retail firms. For many companies, their competitive advantage hinges on their ability to recruit and retain experienced older workers with critical skills (Albright \& Cluff, 2005).

However, there is evidence that the strengths possessed by senior employees are very appropriate for certain types of work, but perhaps not for other types. There are positions which are often better served by their younger counterparts. Over a time period spanning many decades, researchers have well-documented a differentiation between two broad types of intellectual abilities across the adult life span. These are (1)fluid intellectual abilities - termed "Gf" and (2) crystallized intellectual abilities - termed "Gc" (Cattell, 1987). The research indicates a gradual decline in fluid intelligence as one ages. In turn, this type of intelligence is associated with working memory, abstract reasoning, attention, and processing of novel information. Most research shows that maximum levels of Gf are normally reached in the early twenties and steadily declines thereafter (Schaie, 1996). High $\mathrm{Gf}$ is associated with extroversion and openness to new experiences and technology. Some positions which especially require this orientation include computer scientists, mathematicians, and scientists. 
On the other hand, crystallized intellectual abilities $(\mathrm{Gc})$ tend to increase with age. These represent broad aspects of educational or experiential knowledge and are associated with general knowledge, extent of vocabulary and verbal comprehension (Cattell, 1987). High Gc is associated with more conscientiousness, emotional control, higher level goals, and desires to promote the interests of others. Some of the positions which require high Gc are salespersons, managers, supervisors, human relations specialists, and trainers. Most small retailers probably require some combination of Gc and Gf skills, given the wide range of responsibilities and duties which are assigned to individual employees. In turn, older individuals can compensate for declines in Gf by selecting jobs and goals and by using strategies that optimize existing Gc knowledge and skills (Baltes \& Baltes, 1990). In general, older workers excel in jobs and companies where high $\mathrm{Gc}$ is required. However, they may be able to function well in environments associated with High Gf if they are willing to exert the effort needed to master the skills which are required. Still, employers should face the reality that seniors may perform well in some kinds of jobs but not in others.

There are indications to the effect that numerous managers are not heavily motivated nor successful in recruiting and retaining senior employees. One informed source speculates that, “. . . in the United States, a better job of managing industrial scrap is done than that of managing careers of older workers -- at least companies recognize the values to be derived from industrial scrap and there is not a similar acknowledgment of the value gained from the appropriate use and development of the older work force" (Greller \& Stroh, 2004). An inquiry cited in the Human Resources Department Management Report has indicated that more than half of the organizations surveyed did not target older workers in their recruiting efforts and those that did relied most on employee referrals and networking (Anonymous, 2003). Another source states that a study has revealed that two-thirds of U.S. employers do not actively recruit older workers, more than half do not actively attempt to retain key ones, and $80 \%$ do not offer any special provisions (such as flexible work arrangements) (Dyctwald, Erickson, \& Morison, 2004). Further, many senior employees tend to receive lower rates of pay than their junior counterparts (Gangl, 2005). One study revealed that fewer than ten percent of the organizations surveyed provided training and retaining for older employees, organizations were less likely to be adjusting training methods to accommodate the needs of older employees, and there was little attempt to provide age awareness training to managers of older employees (ArmstrongStassen \& Templer, 2005).

One source reports that older workers face bias and stereotyping, that most victims of discrimination are not made whole, and that society's lack of concern for this type of discrimination may prove to be more costly in the future as employers pay more to obtain older workers to fill projected workforce gaps (Grossman, 2005). The term "ageism" appears repeatedly in the literature, and refers to prejudice and discrimination directed toward older persons (Rupp, Vodanovich, $\&$ Crede, 2005). It is sometimes referred to as the third great ism of our society 
(following racism and sexism). Palmore (1999) has explained that ageism involves both prejudice and discrimination, both stereotypes and attitudes, and therefore both cognitive and affective processes. Research has indicated that ageism is even more prevalent in today's society than sexism and racism, although it is typically much more difficult to detect (Levy \& Banaji, 2002). A meta-Analytic investigation on ageism has discovered that older individuals are generally perceived less favorably than those who are younger (Kite \& Stockdale, 2004).

It appears that there is considerable research and opinion on the advantages and disadvantages of utilizing seniors in the work force, for the economy at large, in various sectors, and in individual companies. However, there is no existing literature on the situation that exists for the small retailer grouping. The present study was directed to uncovering insights on this application.

\section{The Research Theory}

A study was undertaken to provide insights into the extent to which small retailers hire seniors, the advantages which these employers associate with these workers, problems associated with these employees, and anticipated future hiring of seniors. A questionnaire was constructed, based upon an earlier study focusing upon the hiring of seniors (Peterson, 1990). This instrument was oriented to the needs of the present study and then pretested among 20 small business retailers in the community where the researcher resides, and subsequently modified in accordance with feedback emanating from the results of the pretest.

The researcher mailed packets of questionnaires to 100 directors of small business institutes or similar agencies providing small business consulting assistance at 100 United States colleges and universities in 41 states. The survey respondents were selected at random from the Membership Directory, International Council for Small Business. Each survey respondent who was included in the sample received ten questionnaires and a request to distribute these to ten randomlyselected current and past small retailer consulting clients. After completing the questionnaires, the clients returned them to the professors, who in turn mailed them to the researcher in self-addressed stamped envelopes. The total usable sample was 302 (a 30.2 response rate).

In the questionnaire, the small retailer respondents were asked if they currently employ or have in the past employed seniors (defined as persons sixty-five years of age or older) and, if they did, for the proportion of their work force that was comprised of members of this group. If they did not employ any seniors, they were instructed not to respond to further questions contained in the questionnaire, except for the last one, which asked if they planned to employ larger or smaller numbers of older persons in the future. Those who currently employ seniors or once had done so were queried as to their perceived advantages and disadvantages of employing seniors in their respective companies. Further, they were asked to estimate if they would hire more or less or about the same proportion of older workers in the future as they have to date. 


\section{Research Results}

The questionnaire asked the respondents if their firms employed seniors at present or did so sometime in the past. A total of 238 ( 78.8 percent of the total) responded in the affirmative. A $t$ test reveals that this percentage was significantly larger than the percentage who indicated that they do nor or did not hire seniors, at the .05 level. Table 1 sets forth the percentage of the surveyed companies' work forces that, at present, included seniors. A total of 211 respondents indicated that they currently employ older workers.. In this case, the majority are in the one percent to 4.9 percent category. In turn, the second largest classification was in the $5.0 \%$ to $9.9 \%$ grouping. In turn, the median percentage was 3.8 percent. In contrast, approximately sixteen percent of the United States population is made up of persons age 65 and older (U.S., 2005). However, it should be recognized that many older persons do not choose to or cannot work, so a direct comparison of employment status and percent of the population can be somewhat misleading. Overall, seniors make up 3.2 percent of the labor force (U.S. Department of Commerce, 2005). These figures suggest that small retail employment of older persons slightly exceeds that of business in general.

\section{Table 1}

Percentage of Respondents' Current Workforces Comprised of Seniors

\begin{tabular}{lcc}
\hline & \multicolumn{2}{c}{ Frequency } \\
Percentage of Workforce & Number & Percent \\
\hline $1-4.9 \%$ & 113 & $53.6 \%$ \\
$5-9.9 \%$ & 42 & 19.9 \\
$10-14.9 \%$ & 17 & 8.1 \\
$15-19.9 \%$ & 19 & 9.0 \\
$20-24.9 \%$ & 9 & 4.3 \\
$25 \%$ and over & 11 & 5.1 \\
Total & $\mathbf{2 1 1}$ & $\mathbf{1 0 0 . 0 \%}$ \\
\hline
\end{tabular}

Older persons might be more successful in attaining and retaining positions in small retail establishments if managerial attitudes were altered. There is anecdotal evidence to support the claim that the ideal candidate is a single new college graduate who is very computer savvy and is willing to work numerous hours per week, while older workers are viewed as dinosaurs (Weinberg, 1998). Some employers are characterized by stereotypes regarding the potential ability of seniors (Prewitt, 2002). In the United States there is a cultural orientation among some managers toward worship of youth and a preference for acquiring "new blood" by replacing older with younger employees (Snape \& Redman, 
2003). Such attitudes may impair the ability of seniors to acquire and maintain employment at the small retailer level.

The respondents were asked, through an open-end question, to cite the advantages, based upon experiences in their companies, of employing seniors. In turn, these responses were coded by three Ph.D. graduate student analysts into categories. The author provided training and practical instruction in code development to the analysts prior to their involvement in the research. The coding scheme was established by each individual student first scrutinizing the respondents' cited advantages, then developing relevant categories, and finally by meeting with other students to discuss and arrive at a consensus as to the most valid and reliable set of composite categories. All this was done under the guidance of the author. This methodology is widely-used in content analysis and there is considerable evidence as to its validity and reliability (Larson, 2002; Cameron \& Trope, 2004). Once the classification scheme was established, the students assigned each survey response to a category. Differences of opinion were resolved through discussion by the three analysts. Once this allocation to categories had been completed, the tabulation process was undertaken. Table 2 outlines the frequencies associated with each category of response.

Table 2

\section{Cited Advantages of Employing Seniors}

\begin{tabular}{lcc}
\hline \multicolumn{1}{c}{ Advantage } & Number of respondents* & Percent of Total \\
\hline Productive & 206 & $18.8 \%$ \\
Experienced & 172 & 15.6 \\
Possess work ethic & 153 & 13.9 \\
Trustworthy & 111 & 10.1 \\
Responsible & 109 & 9.9 \\
Reliable & 95 & 8.6 \\
Punctual & 69 & 6.3 \\
Mature & 53 & 4.8 \\
Respect authority & 49 & 4.6 \\
Loyal to company & 21 & 1.9 \\
Interpersonal skills & 17 & 1.5 \\
Flexible work scheduling & 14 & 1.3 \\
Limited family responsibilities & 8 & 0.7 \\
Other & 22 & 2.0 \\
Total & $\mathbf{1 0 9 9}$ & $\mathbf{1 0 0 . 0 \%}$ \\
\hline
\end{tabular}

*The number of responses exceeds the sample size, since all sample members surveyed cited more than one advantage. 
Several advantages received substantial numbers of frequencies. These were productive, experienced, possess work ethic, trustworthy, and responsible. These were followed by reliable, punctual, mature, and respect authority. Smaller frequencies were associated with loyal to company, interpersonal skills, flexible work scheduling, limited family responsibilities, and other.

Table 3 sets forth the disadvantages of employing seniors which the respondents reported in the survey. In terms of raw numbers (from Tables 2 and 3 ) the advantages outweigh the disadvantages 1099 to 486 (over two to one), furnishing some evidence that small retailers are impressed with the performance of these individuals.

The disadvantages which received the largest number of frequencies are physical restrictions, lack of desire to receive training, opinionated, slow paced, and difficult to train. These are followed by absent minded, do not identify with younger employees, expensive medical benefits, and illness. Receiving smaller frequencies are difficulty in multitasking, excessive complaining, limited computer skills, criticize other employees, only available part time, excessive attention to details, and other.

Table 3

Cited Disadvantages of Employing Seniors

\begin{tabular}{lcc}
\hline \multicolumn{1}{c}{ Disadvantage } & Number of respondents ${ }^{*}$ & Percent of Total \\
\hline Physical restrictions & 73 & $15.0 \%$ \\
Lack of desire to receive training & 70 & 14.4 \\
Opinionated & 66 & 13.6 \\
Slow paced & 52 & 10.7 \\
Difficult to train & 49 & 10.1 \\
Absent minded & 34 & 7.0 \\
Do not identify with younger employees & 33 & 6.8 \\
Expensive medical benefits & 27 & 5.6 \\
Illness & 27 & 5.6 \\
Difficulty in multitasking & 14 & 2.8 \\
Excessive complaining & 10 & 2.1 \\
Limited computer skills & 8 & 1.6 \\
Criticize other employees & 5 & 1.0 \\
Only available part time & 5 & 1.0 \\
Excessive attention to details & 4 & .8 \\
Other & 9 & $\mathbf{1 0 0 . 0} \%$ \\
Total & $\mathbf{4 8 6}$ & \\
\hline
\end{tabular}

* The number of responses exceeds the sample size, since all sample members surveyed cited more than one advantage. 
The sample members were requested to specify if they planned to employ larger percentages of seniors in their work forces in the future than they had in the past. The responses were $197(65.2 \%)$ yes, $71(23.5 \%)$ no, and $34(11.3 \%)$ don't know. The percentage noting "yes" was significantly greater than the percentage noting "no" according to a $t$ test at the .05 level. Overall, it appears that small retailers intend to rely more on older workers with the passage of time.

\section{Discussion}

The research upon which this paper was based was undertaken to assess the degree to which small retailers employed older workers, perceived advantages and disadvantages of employing these individuals, and planned future hiring of seniors. A large number of the respondents employ older workers, although their percentage of the work force is not great. The respondents set forth a number of advantages, indicating that older workers have substantial potential for various types of small retailers. The advantages cited by the respondents emphasized productiveness, experience, possession of the work ethic, trustworthiness, responsibility, and reliability. Firms that seek these advantages may desire to consider increasing their employment of seniors.

There are disadvantages of employing seniors and these should be considered by potential employers. The major disadvantages reported by respondents were physical restrictions, lack of desire to receive training, opinionated, slow paced, difficult to train, and inability to identify with younger employees.

Finally, a high percentage of the respondents plan to employ more older workers in the future. This suggests that small retailers may be becoming increasingly aware of opportunities available through the hiring of these individuals. This could signal more competition from other companies, in attracting seniors into positions of employment.

This study had several limitations. The respondents were asked to set forth their plans and intentions for hiring seniors in the future. It is possible that a number of respondents had no specific plans and/or could not forecast their future actions and therefore had to guess when providing this information. The sample selection process was not entirely random, although an attempt was made to approximate this status. Further, some retailers may not be fully aware of the specific advantages and disadvantages of employing seniors, especially if these respondents do not work closely with their employees. Finally, when coding of responses is employed, some degree of subjectivity is introduced into the analysis. It should be recognized that this may have introduced bias into the assessment of research results.

The results of the study give rise to some implications for small retailers. It is apparent that these companies will experience a number of specific advantages, as well as disadvantages, as a result of employing older workers. They will employ even larger numbers in the future than in past periods. For some this will involve continuing to employ current workers past normal retirement dates. For others, 
it will require hiring new employees from the ranks of the elderly. Both of these strategies should be considered by forward-looking managers.

The substantial number of advantages set forth by the sample members suggests that small retailers who are not committed to well-conceived programs to recruit and retain older workers may be overlooking a significant potential pool of managerial and operative talent. This is particularly the case for those regions and retail industries which now are or will experience personnel shortages and deficiencies in the capabilities of current employees. Recruitment and retainment programs targeted at older job seekers may hold substantial promise for these firms. Hence, those who are not already using such programs may be well-advised to do so.

Small retailers who are contemplating the employment of older workers should consider the particular advantages and disadvantages revealed through the study. If, for instance, productiveness, experience, possession of the work ethic, trustworthiness, responsibility and reliability and other advantages set forth in Table 2 are of considerable importance to the firm, seniors may be a very good source of applicants and personnel to retain. On the other hand, if the position in question would not be appropriate for those with physical restrictions, lack of desire to receive training, opinionated personalities, slow paced, difficult to train, or other disadvantages specified in Table 3, the employer may approach the senior applicant and retention pool with caution, unless modifications, such as alterations in the nature of the work or training programs for seniors can be readily activated.

When seniors are recruited, small retailers may have to rely on different sources of job applicants than is the case for recruiting their younger counterparts. Some senior citizen centers are involved in placing members who seek employment. There are firms that have developed their own senior citizen temporary help pools, frequently composed of ex-employees. Small retailers who seek senior employees may be well-advised to consider these alternative sources.

When older workers are hired or retained, the small retailer may find it to be advantageous to alter some methods of supervising employees and arranging their work. Since older workers are experienced, possess the work ethic, are trustworthy, responsible, and reliable, they may require less close supervision. It may be advisable to convert some positions to part-time or job-sharing or to utilize flex-time, if these are not already in place. Some job responsibilities may have to be redesigned, so that they are less physically demanding. Arrangements, such as furnishing transportation from senior centers to workplaces, may be useful.

In some cases, training procedures and content may require deviations from those employed for younger employees. Since many older workers are experienced, their training may not need to be extensive. In some cases, adjustments may be needed in the training format, as in presenting materials slower to older workers than for their younger counterparts. A positive development is that the training benefits may accrue to the small retailer in more permanent form for seniors, since their turnover tends to be less and they are less likely to move on to 
other firms after they have obtained valuable training from their current employer and have adjusted to the work environment of the small retailer.

What do seniors want in their work-related activities, environment, and relationships with others? Of course, there is considerable variation from one person to another. However, a number of generic and widely held desires have been uncovered through research efforts. Basically, these individuals prefer some degree of control over the tasks they perform on the job (Moyers \& Coleman, 2004). In turn, they are predisposed toward work that promotes their health and safety (Moyers \& Dale, 2004). There is evidence that they place substantial value on career autonomy (Karp, 1987). In addition, they prefer quality rather than quantity of production and favor working at their own pace (Kelly, 1990).

Generally, older workers have a desire for variety and the possibility to choose among tasks (Rix \& Chusmir, 1990; Kelly, 1990). In addition they prefer supportive and understanding supervisors who recognize their experience and maturity (Rupp, Vodanovich, \& Crede, 2005; Ramsey, 1993). They like feeling useful to the organization and to society at large (Zetlin, 1992). In this regard, they are motivated toward obtaining affective rewards (emotional satisfaction) and activities which support their identities. Many of these individuals want to assume new roles, such as mentors, trainers or consultants (Sheppard, 1988).

Most older workers seek enjoyment of the same opportunities as younger workers and equal access to training, career advancement, and career development (Dychtwald, Erickson, \& Morison, 2004;Siegel, 1993). They want to be heard, to be fairly compensated for their contributions to the organization, and to be recognized for their qualifications (Rix \& Chusmir, 1990). In addition, they often prefer adjustments to their work function, such as part time work, job sharing; phased retirement, and working during early hours of the day (Challenger, 2004; Purcell, 2005; Dibden \& Hibbett, 1993).

How can small business retailers improve their efforts directed to to attracting and retaining older workers? One tested approach is "positive psychology," an avenue that has emerged and gained momentum and that redirects focus from what is wrong with people toward one that emphasizes human strengths that allow individuals to thrive and prosper. The goal is to create organized systems that actualize human potential. This requires taking steps to accentuate the positive by recognizing the capabilities of older employees as potential exceptional learners and performers. Then, seniors are encouraged to employ the resources that they have learned through education, training, and experience to grow professionally and to lend their capabilities to the resources of the organization and the efforts of co-workers (Peterson \& Spiker, 2005).

There are a number of other actions which small retail managers can take to acquire and retain needed older workers. According to one source, useful practices toward this end are flexible work arrangements, time for individual (not professional) development, insurance and retirement benefits, training, and compensation policies tailored toward the needs of seniors (Wellner, 2002). Another source suggests training to upgrade the skills of older workers, providing 
opportunities for them to transfer to more desirable jobs, furnishing attractive benefits such as health care, long term care insurance, elder care and flextime, and institute-phased retirement programs. (Fusaro, 2001; Kindelan, 1998). Yet other authorities favor providing time for individual development - as opposed to professional development (Wellner, 2002) and maintenance of a balance between work and personal goals (Smola \& Sutton, 2002).

Other policies for attracting and retaining older workers are available. Some relate to recruiting practices. In this regard, companies are urged to alter the appearance and placement of recruiting advertisements, expand company recruiting policies, and train employees on how to interview older job applicants (Sullivan \& Duplaga, 1997). Other policies focus on retaining older members of the work force. The suggestions include auditing the company culture, rethinking and changing attitudes toward older employees in the workplace, discussing age discrimination and other adult issues with other companies, and developing a friendly environment for older adults. Another possibility is to change stereotypical beliefs of younger workers, many of whom have negative impressions regarding the training, promotion, and retention of older workers (Chiu, Chan, Snape, \& Redman, 2001).

For some small business retailers, alterations in the physical workplace can be of value in attracting and retaining seniors.

No one wants to live or work in a misdesigned world, where light is too dim, words are unintelligible, switches are too fussy, and objects are too heavy to lift. Yet older people face exactly this problem if steps are not taken to design a more hospitable environment. Older workers will feel weak, frail, and dependent, creating lower morale, less productivity, and more missed time. The good news is that designing for the older worker is simply good design. The effort spent creating a suitable environment for older people will increase safety and productivity of all workers (Green, 2002).

In this same vein, one source calls for the redesign of safety programs in the workplace to address the special needs of older workers. Prevention of on-thejob injuries can lead to lower costs associated with employing older workers, while still managing the injuries characteristic of younger workers. Effective accident prevention programs can be of value in reducing both injury frequency and severity (Findley \& O Bennett, 2002).

One authority sums up the suggestions for utilizing older workers as "providing seniors with a satisfying career" (St. Edmunds \& Pullin, 1998). Another sums it up by specifying furnishing seniors with want fulfillment (Easton, 2002).

Dychtwald, Erickson, and Morison (2004) have developed a program for recruiting and training older workers. Their recommendations appear in Figure 1. Moyers \& Coleman (2004) provide suggestions for the purposes of recruiting and retaining senior workers. These are set forth in Figure 2. 


\section{Figure 1}

\section{Dychtwald, Erickson and Morison Program for Recruiting and Training Older Workers (2004)}

\section{Create a culture that honors experience}

a. In recruiting advertisements emphasize "experience," "knowledge" and "expertise," rather than "energy," "fast pace," and "fresh thinking."

b. Recruit through city agencies, the National Council on Aging, and community organizations.

c. For interviewing-use a technique such as role-playing to gauge candidates' ability to handle customers, rather than building something with legos or verbal gymnastics.

d. Make training (including refresher training) available to older workers.

e. Create a culture that values older persons' experience and capabilities.

\section{Offer flexible work}

a. Design jobs so that staying on is more attractive than leaving

b. Make work less time-consuming and pressured

c. Use flex-work-flexible in both where and when work in performed

d. Use compressed workweeks, job sharing, and part-time schedules

e. Allow those with fiexible work to be considered for promotions

f. Allow employees to redesign their jobs

\section{Introduce flexible retirement}

a. Allow retirement after age 65

b. Allow retirees to work periodically for the firm as consultants or independent contractors

\section{Figure 2 \\ Moyers \& Coleman Suggestions for Recruiting and Retaining Older Workers (2004)}

a. Adjust the physical demand of the job, e.g., heavy lifting, to the capabilities of seniors

b. Instruct older workers on how to adjust to changes in technology

c. Strike a balance between job enrichment and repetitiveness

d. Improve the work environment, as through better lighting, decreasing glare, and larger print on written materials

e. Provide recognition for superior performance

f. Change the culture of the company so that it dispels myths regarding older worker ability 


\section{Conclusion}

Overall, seniors have the potential for assisting a number of small retailers in fulfilling their personnel needs. While adjustments may have to be made in recruiting, hiring, training, and supervising practices, the net result may be very positive for those retailers who choose to employ this class of personnel.

\section{References}

Adams, S. J. (2002). Passed over for promotion because of age: An empirical analysis of the consequences. Journal of Labor Research, 23, 446-461.

Albright, W. D. Jr., \& Cluff, G.A. (2005). Ahead of the curve: How Mitre recruits and retains older workers. Journal of Organizational Excellence, 24, 53-63.

Anonymous. (1999). The wisdom of older workers. Management Services, 43, 6-8.

Anonymous. (2001). Financial executives seek 'soft' skills when evaluating job applicants. AFP Exchange, 21, 65-68.

Anonymous. (2003). Older workers will be critical for workplace planning, studies show. Human Resources Department Management Report, 3, 12-13.

Armstrong-Stassen, M.., \& Templer, A. (2005). Adapting training for older employees: The Canadian response to an aging workplace. Journal of Management Development, 24, 57-67.

Baltes, M. M., \& Baltes, P. B. (1990). Psychological perspectives on successful aging: The model of selective optimization and compensation. In P. B. Baltes \& M. M. Baltes (eds.) Successful Aging Perspectives from the Behavioral Sciences. (pp. 1-34). New York: Cambridge University Press.

Barrier, M. (2002). An age-old problem. HR Magazine, 47, 34-37.

Bell, J. (2001). Career crossroads. Journal of Property Management, 66, 42-46.

Bushko, D., \& Raynor, M.. (1999). More on the aging worker: Who are they and how can they stay vital? Journal of Management Consulting, 10, 68-69.

Cameron, J, A., \& Trope, Y. (2004). Stereotype-biased search and processing of information about group members. Social Cognition, 22, 650-672.

Cattell, R. B. (1987). Intelligence: Its Structure, Growth, and Action. Amsterdam: North Holland.

Challenger, J. A. (2004). Waking up to the senior worker. Futurist, 38, 19-20. 
Chiu, W., Chan, A., Snape, E., \& Redman, T. (2001). Age stereotypes and discriminatory attitudes toward older workers: An east-west comparison. Human Relations, 54, 629-661.

Crampton, S., Hodge, J., \& Mishra, J. (1996). Transition-ready or not: The aging of America's workforce. Public Personnel Management, 25, 243-256.

Dibden, J., \& Hibbett, A. (1993). Older workers: An overview of recent research. Great Britain Department of Employment-Employment Gazette, 101, 237-250.

Dychtwald, K., Erickson, T., \& Morison, B. (2004). It's time to retire retirement. Harvard Business Review, 82, 22-34.

Easton, L. J. (2002). Let's bring down age retention barriers. Nursing Management, 33, $17-19$.

Findley, M. E., \& O'Bennett, J. (2002). Safety \& the silver collar worker. Professional Safety, 47, 34-38.

Finegold, D., Mohrman, S., \& Spreitzer, G. M. (2002). Age effects on the predictors of technical workers' commitment and willingness to turnover. Journal of Organizational Behavior, 23, 655-674.

Fusaro, R. (2001). Needed: Experienced workers. Harvard Business Review, 79, 20-21.

Gangl, M. (2005). Income inequality, permanent incomes, and income dynamics: Comparing europe to the united states. Work \& Occupations, 32, 140-162.

Green, M. (2002). Environmental design for the older worker. Occupational Health and Safety, 71, 47-49.

Greller, M. M.,. \& Stroh, L. K. (2004). Making the most of late career for employers and workers themselves: Becoming elders not relics. Organizational Dynamics, 33 , 202-214.

Grossman, R. J. (2005). The under-reported impact of age discrimination and its threat to business vitality. Business Horizons, 48, 71-78.

Halachmi, A. (1998). Dealing with employees over fifty: Reflections and an introduction. Public Productivity \& Management Review, 22, 6-14.

Karp, D. (1987). Professionals beyond midlife: Some observations on work satisfaction in the fifty-to-sixty decade. Journal of Aging Studies, 11, 209-223.

Kelly, J. (1990). Employers must recognize that older people want to work. Personnel Journal, 27, 44-47. 
Kindelan, A. (1998). Older workers can alleviate labor shortages. HR Magazine, 43, 200-207.

Kite, M. E., \& Stockdale, G. D. (2004). Attitudes toward younger and older adults: An updated meta-analysis review. Journal of Social Issues, 27, 42-58.

Kraut, A. I (2005). Retirees: A new resource for American industries. Personnel Administrator, 22, 26-29.

Larson, M. S. (2002). Race and interracial relationships in children's television commercials. The Howard Journal of Communications, 13, 223-235.

Levy, B. R., \& Banaji, M. R. (2002).Implicit ageism. In Nelson. T. D. (ed) Ageism: Stereotypes and prejudice against older persons. (pp.49-75). Cambridge, MA: MIT Press.

McEvoy, G. M., \& Blahna, M. J.( 2001).Engagement or disengagement! Older workers and the looming labor shortage. Business Horizons, 44, 31-49.

McShulskis, E. (1997). Older workers in demand. HR Magazine, 42,18-23.

Minerd, J. (1999). A 'gray wave' of entrepreneurs. The Futurist, 33, 10-14.

Moyers, P. A., \& Coleman, S.D. (2004). Adaptation of the older worker to occupational challenges. Work, 22, 71-78.

Moyers, P. A., \& Dale, L. M. (2004). Challenges and opportunities for the older worker. Work, 22, 3-4.

Palmore, E. B.(1999). Ageism: Negative and positive. New York: Springer Publishing Company.

Peterson, R. (1990). Large retail firm involvement in hiring senior citizens. Business Journal, 16, 53- 68.

Peterson, S. J., \& Spiker, B. K. (2005). Establishing the positive contributory value of older workers: A positive psychology perspective. Organizational Dynamics, 34 , 153-167.

Prewitt, M. (2002). Senior moment: Chains forget older customers. Nation's Restaurant News, 36, 1-4.

Purcell, P. (2005). Older workers: Employment and retirement trends. Journal of Pension Planning \& Compliance, 30, 49-70.

Ramsey, R. D. (1993). What it takes to supervise older workers. Supervision, 54, 9-10. 
Rix, C., \& Chusmir, L. (1990). A shift in values is squeezing older people. Personnel Journal, 24, 48-52.

Rupp, D., Vodanovich, S. J., \& Crede, M. (2005). The multidimensional nature of ageism: Construct validity and group differences. The Journal of Social Psychology, $145,335-362$.

Schaie, K. W. (1996). Intellectual development in adulthood: The Seattle Longitudinal Study. New York: Cambridge University Press.

Siegel, S. R. (1993). Relationships between current performance \& likelihood of promotion for old versus young workers. Human Resource Development Quarterly, 4, 39-50.

Sheppard, H. (1988). Work continuity versus retirement: Reasons for continuing work. In R. Morris \& S. Bass (eds.) Retirement reconsidered: Economic \& social roles for older people. (pp. 103-137). New York: Springer Publishing Company.

Smola, K. W., \& Sutton, C. D. (2002). Generational differences: Revisiting generational work values for the new millennium. Journal of Organizational Behavior, 23, 363-382.

Snape, E., \& Redman, T. (2003). Too old or too young? The impact of perceived age discrimination. Human Resource Management, 13, 78-90.

St. Edmonds, B., \& Pullin, J. (1998). Parable of the talents. Professional Engineering, $11,33-39$.

Sullivan, S. E., \& Duplaga, E. A. (1997). Recruiting and retailing older workers for the new millennium. Business Horizons, 40, 65-69.

Swanson, C. E., Kopecky, K. I., \& Tucker, A. (1997). Technology adoption over the life cycle and aggregate technological progress. Southern Economic Journal, 63, 872-887.

Tschirhart, M. (1998). Understanding the older stipended volunteer: Age-related differences among Americorps members. Public Productivity \& Management Review. $22,35-48$.

U.S. Department of Commerce, Bureau of the Census (2005). Statistical Abstract of the United States 121 st Edition, 38.Washington, D.C.: U.S. Government Printing Office.

Van Yoder, S. (2002). Coping with the graying workforce. Financial Executive, 18, 2629.

Welbourne, T. M., \& Cyr, L. A. (1999). The Human resource executive effect in initial public offering firms. Academy of Management Journal, 42, 616-629.

Weinberg, N. (1998). Career crisis. Network World, 15, 1-5. 
Wellner, A. S. (2002). Tapping a silver mine. HR Magazine, 47, 26-32.

Zetlin, M. (1992). Older \& wiser: Tips to motivate the 50's crowd. Management Review, $35,30-33$.

Robin T. Peterson is Distinguished Professor of Marketing, College of Business, New Mexico State University, Las Cruces, New Mexico. He received the Ph.D. in Marketing from the University of Washington and has written articles and books in the fields of marketing, small business, and business ethics. 